\title{
Rehabilitating functional mangrove ecosystem
}

\author{
Deiva Oswin Stanley Ph.D.
}

Stanley DO. Rehabilitating functional mangrove ecosystem. J Environ Geol 2017;1(1):31-32.

\begin{abstract}
Planting mangroves has been projected as a well-known technique for restoring mangrove ecosystem. However, the greater parts of planting endeavors neglect to reestablish functional mangroves and leave lessons for us to realize which we advantageously overlook. Utilizing confined mangrove species, especially from the families, Rhizophoracea and Aviceniaceae along an uncovered coastline in too-deep water, generally in the lower half of the intertidal system, from mean sea level down to lowest tide where mangroves, do not normally develop are the reasons behind mangrove planting projects' disappointment (1). Aside from absence of suitable technical appraisal, the lower inter-tidal mudflats or sea grass beds or sandy shorelines are frequently chosen for planting mangroves. These delicate ecosystems are targeted for planting seedlings, because degraded mangroves are oftentimes connected to tenurial issues that require noteworthy effort to address (2). Converting habitats by planting mangroves can obliterate the crucial habitats with unique biodiversity and add to their further destruction.
\end{abstract}

Worldwide restoration endeavors and much cash were spent in creating mangrove seedling nurseries, while minimal expenditure or time is set into deciding the site-particular needs of mangroves at every restoration area. Stripping seeds from a chosen stand for creating nursery year after years to provide seed material for large numbers of hectares of planting plans by government and non-governmental initiatives, meddle with the characteristic recovery of the current mangrove stands and kill the foundation chance of future normal mangroves (3). India ought to concur upon with the correct approach, the Ecological mangrove restoration [EMR] which has been executed and recorded for decades in new world mangrove systems and is a best practice for adaptation.

Ecological mangrove restoration (EMR) is defined as: "an approach to coastal wetland rehabilitation or restoration that seeks to facilitate natural regeneration in order to produce self sustaining wetland ecosystems." (4). The steps for a successful EMR, as described by mangrove researcher Lewis, and Mangrove Action Project are: 1. Understanding the species ecology (reproduction, dispersal, seedling establishment) 2. Understanding hydrological patterns determining seedling distribution and establishment 3. Assessing man-made modifications to the environment that may be preventing natural colonization 4 . Selecting the most appropriate restoration site possible, using information from Steps 1-3. Besides assessing physical and ecological parameters as above, this step also involves anticipating and resolving community issues such as land tenure and land use, to allow longterm access to the site and the sustainability of conservation. 5. Designing the restoration site to restore appropriate hydrology and natural recruitment and 6. Only actively plant propagules and seedlings if step 4 will not be successful or rapid vegetation cover is required (4).

EMR approach works with physical procedures, particularly land elevation and hydrology, to guarantee success for appropriate site and selected mangrove species. Ways in which this can be accomplished incorporate, increasing the elevation of the site and augmenting channels to enhance hydrology, therefore facilitating the input of propagules from elsewhere. In permitting mangrove propagules to disperse inside a range normally, it diminishes the need to physically plant propagules. This may bring about a reasonable EMR venture with consistent supply of propagules for the development of a functional forest. The components which will control the choice of mangrove species for the EMR procedure are: (i) species-particular attributes, for example, resistance to flooding (ii) site qualities including elevation, height of tides and so on (iii) accessibility of propagules in the region to disperse to the objective site (iv) tidal flooding, which expands the landward reach of waves and currents (v) wave and current patterns and (vi) size of area (4).

Ecological restoration techniques have been utilized to effectively reestablish 30 mangrove destinations in the United States, alongside mangroves in another 25 nations around the globe (5). Contribution of community in EMR at small and medium scales depends on its capacity to resolve both biophysical and socio-political issues underscoring mangrove degradation. Indonesia has succeeded in reestablishing 60000 ha of disused shrimp ponds through Community Based EMR and strategic breaching of ponds says Brown et al. We recommend perusing the Ecological Mangrove Rehabilitation - A Field Guide for Practitioners by Roy Robin Lewis and Ben Brown, 2014 which furnish professionals with exercises, apparatuses and alternatives to be utilized as a part of surveying, outlining, executing and observing a mangrove restoration venture.

Natural mangroves demonstrate a reasonable land-to-sea zonation with various species. All species cannot similarly withstand the submerged conditions, waves and saltiness happening at the seafront. Regular mangrove progression begins with pioneer species that encourage colonization by different species. In general, planted species are not pioneers therefore; the regular zonation and colonization process is interfered. Rather, when the biophysical, social and economical conditions are set up back amid reclamation, nature will do the rest. Mangroves will restore normally, without planting, as propagules are naturally brought in by the tides. To enhance the common recovery process, biodiversity and survival, planting may be also carried out as an option. (6).

Ecologically reestablished mangroves survive and functions better. Restored mangroves with various species and characteristic zonation indicate more prominent assortment in root systems, tree sizes, foliage, fruits and natural products, fulfilling different functions and attracting diverse fauna. It also provides several merchandise [timber, feed, nectar, natural products, and fish] and services [coastal protection, carbon stockpiling, water filtration, fisheries improvement]. Naturally reestablished mangroves are resilient to the impacts of natural calamities. Reestablishing the connectivity between adjacent ecosystems like sea grass beds or coral reefs enhances advantages.

\section{REFERENCES}

1. Stanley DO, Lewis RR. Strategies for mangrove rehabilitation in an eroded coastline of Selangor, Peninsular Malaysia. Journal of Coastal Development 2009;12(3):144 -56.

2. Brown B, Fadillah R, Nurdin Y, et al. Case Study: Community Based Ecological Mangrove Rehabilitation (CBEMR) in Indonesia, S.A.P.I.EN 2014;7(2).

3. Stanley DO. Mangrove biodiversity conservation strategies, recent advances in biodiversity of India. In: Ramakrishna RC, Sivaperuman C, eds. Zoological Survey of India, Kolkata, 2011: 101-103.

4. Lewis RR, Brown B. Ecological mangrove rehabilitation a field manual

Integrated Coastal Ecosystems Management Specialist, Vadodara, Gujarat, India

Correspondence: Dr. Deiva Oswin Stanley Ph.D, Integrated Coastal Ecosystems Management Specialist, Vadodara, Gujarat, India. Telephone +094 263 34634, e-mail oswinstanley@gmail.com

Received: September 07, 2017, Accepted: September 12, 2017, Published: September 17, 2017

OPEN ACCESS

This open-access article is distributed under the terms of the Creative Commons Attribution Non-Commercial License (CC BY-NC) (http:// creativecommons.org/licenses/by-nc/4.0/), which permits reuse, distribution and reproduction of the article, provided that the original work is properly cited and the reuse is restricted to noncommercial purposes. For commercial reuse, contact reprints@pulsus.com 
for practitioners, publ. restoring coastal livelihoods program 2014:1-251.

5. Hannah W. Mangrove Restoration: Letting mother nature do the work, Smithsonian Institution. 2016
6. Anon. Mangrove restoration: To plant or not to plant. Leaflet by Waterloo foundation, the dutch sustainable water fund and otter foundation and developed by partners of the building with nature indonesia project and partners of the ecoshape consortium 2016. 